\title{
MATLAB Curriculum Teaching Reform of Exploration
}

\author{
Chenghui YANG* \\ College of Electrical Engineering \\ Northwest Minzu University \\ Lanzhou, China \\ *yangchenghui36@163.com
}

\author{
Hongjie BAO \\ College of management \\ Northwest Minzu University \\ Lanzhou, China \\ baohongjie88@126.com
}

\begin{abstract}
This paper puts forward that combined with the teaching method of project cooperation take the place of traditional teaching mode, which is applied to the teaching of MATLAB, putting forward the concrete implementation plan of the teaching and the phases of the concrete implementation measures, which solves the course boring, and students' enthusiasm is not high, and learning disabilities, etc. Through that practice the students' innovative ability and the team cooperation ability. The students' learning attitude was improved obviously and some achievements have been obtained to reform the traditional teaching methods and practice. Practice has proved that these methods can help enhance the students' interest in learning, and improve the quality of teaching, and gradually train students' innovation consciousness, and promote the cultivation of students' comprehensive ability.
\end{abstract}

Keywords-course reform; exploratory experiment; MATLAB; system simulation

\section{INTRODUCTION}

The teaching contents and curriculum system reform is the basis of implementing innovation education project. Curriculum timely absorbent the frontier science and technology, which is the innovation of knowledge, and the content of update, the change of views, weight the translation of reform, should be regularly. MATLAB curriculum is an important application of automation tools, which requires content covering important automatic control parts, SIMULINK dynamic link library application, graphical interface design, structural design of handle part, 2D,3D graphics analysis, etc. Combining closely integrated automation another is the application of electronic technology. Electronic technology by using power semiconductor switching devices of all kinds of electric power transformation and control circuit to realize electrical energy transformation, which is a comprehensive electronic technology, control technology and electric power technology in the emerging interdisciplinary. "Electronic technology" course has become China's colleges and universities undergraduate professional electrical engineering and automation is the most important one of the basic course of discipline. This course involves a large number of circuit analyses, which is a cheek by jowl with and practice course, whose circuit diagram and the waveform is much. Many students think that is very difficult, not easy to master. Traditional blackboard writing teaching and multimedia teaching are not able to effectively solve this problem, because once the parameters of the circuit is changed, its working state changes after the change and the output waveform will change. Using multimedia teaching to the student presentation, generally for several typical waveforms, the waveform of the physical concept and its flexibility is bad, that gives "electronic technology" course teaching of teachers and students on the course of learning difficulties of understanding. And the update of teaching content reform should pay attention to adhere to the basic, breaking down barriers between discipline curriculum and the area of knowledge. Strengthening the logic and structure between curriculum and curriculum system of contact and combination, and promoting related courses' integration '. Introduction to promote the opening of a problematic, integrated, such as types of courses, as well as discipline frontier knowledge lecture.

\section{MATLAB CURRICULUM REFORM CONTENT}

Using MATLAB/SIMULNK software can easily build consistent with actual teaching scenario. Simulation software is introduced by teachers in the teaching, in the teaching of basic variable flow theory, using MATLAB/SIMULINK software to build electronic circuit simulation demonstration, electronic commutation and control field encountered most typical switching circuit simulation model can be established, based on the simulation of the model, which can be intuitive to show the influence of various waveform parameter changes on the circuit diagram and numerical calculation, so that students understand the teaching content, full and accurate teaching scene, which can create a real electronic circuits work scenarios, both concrete and vivid. Besides, still use software to provide parameter setting function. By changing the device parameter values, the students are in learning, who can analyze some parameter value under the condition of working condition and the corresponding waveform of the circuit diagram, and then inputting the corresponding parameter value in the simulation model, the results of their analysis and simulation results. At the same time, in Simulation, the circuit can be used to simulate all kinds of power electronic device failure, such as open circuit and short circuit or loss of the pulse. Students are able to clearly show all kinds of the working process of the power electronic circuit. Enabling students to intuitive, comprehensive grasp of course content. The situation will be interesting, which greatly deepens students understanding of knowledge and enables the students to the theory of tacit knowledge into explicit skills[1]. In MATLAB teaching 
activities, design principle of automatic control and electronic design test and analysis are the core part of the waveform, but also it is the most difficult for students to understand and master. Through the use of MATLAB simulation software, using SimPower-system model library contained in the common power supply module, these modules such as power electronic device module lap can be all kinds of circuit, which can be convenient to be various, such as the current in the circuit, voltage waveform, and conveniently change circuit parameters and different waveform[2,3].

We pay attention to the cohesion between practice and theory course, which includes two aspects:

One is the appropriate treatment from the known to the unknown transition, so that the students can be better, faster to accept new knowledge;

Second, it is to deal with the problem of repeated, in order to improve the students' interest in learning and efficiency.

Therefore, teachers are required to have the ability to solve the problem, namely, a teacher is not only familiar with electronic technology curriculum theory knowledge, who can be targeted, timely for supplement related theory of teaching content, and able to skillfully use the MATLAB simulation software, the electronic technology course and the actual research project. Professional competition experience in organic link can help consolidate and deepen the knowledge, guide the student association and thinking. The MATLAB electronic technology teaching is not a simple repetition, superposition, knowledge accumulation, but of course there is comprehensive utilization, which promotes the development of students' personality, and further develops students' ability of applying theory to practice, stimulate students' learning motivation, learning interest, and the students' creative potential.

\section{MATLAB CURRICULUM REFORM GOAL}

Our teaching goal is to "put this to use, run out of it, thought it was" combining with the corresponding automation.

Professional courses, such as basic circuit, several electric, electric professional course automatic control principle, detection technology, power electronics technology, so the goal of the reform is based on MATLAB electronic technology teaching which is mainly a combination of the students learning professional circuit, electronic technique course students, under the premise that has mastered the theoretical knowledge, through the use of MATLAB simulation software, who can be familiar with electronic technology topology, and applying to the study of power supply and motor learning.

Pay attention to students' innovative ability training, through reforming and strengthening the innovative practice teaching, so as to improve students' theory with practice and independent hands-on ability. The ability to analyze and solve problems is further improved effectively. MATLAB experiment can give students a more broad thinking space and choice, and can play to their own thinking and imagination, inspiring students' innovative consciousness and comprehensive ability and exercise. By optimizing classroom experiments, strengthening extracurricular practice, the students all think through MATLAB experiment study, and harvesting the application of electronic technology.

\section{COURSE CONTENT OPTIMIZATION AND MATLAB TEACHING REFORM}

Early period on the teaching design, teaching, just is teaching circuit transformation. The students' first contact and the actual sense is not much. The circuit voltage and current waveform, the switch, the working principle of pipe and other are difficult to understand. Students need to build a consistent with the actual situation, and students don't master the application of MATLAB simulation software, needing to the scene simulation model which is set up in class. In single phase half controlled bridge rectifier circuit as an example, the circuit diagram is projected onto a large screen, and the teacher should first analyze the composition and working principle of the circuit, and then step by step build MATLAB simulation model of single phase half controlled bridge rectifier circuit. The circuit of the simulation process can be divided into the simulation model set up, setting up the model parameters and observing the results of simulation.

MALTAB electronic technology course teaching reform focuses on theory with practice, focusing on practice, which is conducive to play a "student is the subject of education", and it is advantageous to the students "learning to learn innovative ability and quality training", to achieve the teaching goal, to promote the development of students' personality, and to promote each other between teachers and students the principle of common progress. According to the characteristics of the innovative experiment which is open to college students, we are going to take the following measures in the aspect of method and the experimental teaching means:

\section{A. Developing second classroom activities}

In MATLAB innovative experiment teaching, the experiment courses of open are different from the experiment courses of outline, and experiment time have been reserved between students and instructors. At the same time, we actively organize students to carry out the second classroom activities, guiding the student to participate in academic activities and scientific experiment. With the deepening of the course, students also have the urgent desire, hoping to find skills learned in the practical application to start. So the experiment teaching system must be reformed, increasing the comprehensive experiment of design innovative, opening MATLAB laboratory of the college, more fully using the laboratory equipment, to make the students' ability of MATLAB simulation a qualitative leap, to effectively improve the students' ability to analyze and solve problems, at the same time, stimulating the students' creative ability.

\section{B. Significance of MATLAB}

- Developing and testing the students' ability of applying the theoretical knowledge, mastering the experimental principle, and establishing correct simulation model , which lay a good foundation for students to 
curriculum design, graduation design and take part in the professional game;

- Giving students a more broad thinking space and choice, which can play to their own thinking and imagination, inspiring and exercising students' innovative consciousness and comprehensive ability;

- Cultivating students' perseverance will quality, the scientific attitude of seeking truth from facts and the collaboration of the spirit of mutual help. By optimizing the classroom teaching and strengthening extracurricular practice, the students all think through the study of power electronic technology course, who harvest quite big.

\section{REFORM METHODS}

The main content of the MATLAB simulation experiments including setting up simulation model, setting up the model parameters and observing the simulation results of three processes. Before experiment, teachers spend more time to explain the experimental purpose before experiment, experiment contents, experiment and the experimental steps, etc. As a result, the students don't have to spend much time on their own. Now the instructor adopts part of students' completed basic experiment, such as the establishment of a simple circuit model, parameter modification, etc. Then, instructors open complex circuit experiment content, based on students' mastery of basic experiment part. The students pick up more from the experiment contents which are open to the public interest, and design which is closely related to the living example. In addition, students use their spare time to do the relevant tests, the hardware and software debugging program, in-depth analysis of the experimental results, to further consolidate and digest what they have learned theory knowledge, so as to improve the students' ability of theory with practice and independent to start work, the ability to analyze and solve problems to further improve effectively[4,5].

In a word, the MATLAB teaching reform can make the students opening up the field of vision, promoting the innovative thinking, improving the practical ability and innovation ability on the basis of the study, through the practice of the comprehensive practice and application process.

\section{TO STRENGTHEN THE CONSTRUCTION OF TEACHING STAFF}

MALTAB and power electronic technology course construction is the key to teachers, who have irreplaceable important position in the quality education as the goal of course construction and reform. Improving teachers' ability and comprehensive quality, is the basic premise of strengthening and improving college students' quality-oriented education, also is the key to implementing quality-oriented education. Through the above aspects to the construction of the teaching content based on MATLAB and reform research and practice, which has the following features:

\section{A. Innovative Experiment}

Novel, and the related domestic and international academic conferences, new theory and new technology seminar, subject development and dynamic report released information on the Internet such as timely, can meet the needs of teachers and students teaching and learning;

\section{B. Open Experiment}

Instructor guidance are experienced, the use of modern means to improve the students' learning interest in electronic technology course, deepening the students understanding of the content;

\section{Electronic technology combined with simulation experiments}

Both in teaching theory and the experiment teaching to the student extracurricular life, is advantageous to the students' learning and resources sharing, improve the quality of teaching and talent training quality.

\section{MATLAB electronic technology course practice teaching link into classroom.}

Focus, extracurricular experiment of three parts, the experiment content from the basic operation, validation experiments to explore, innovation and application of comprehensive practice, develop the students' field of vision, cultivate students' innovation ability, engineering practice ability and scientific research ability. On the basis of which guiding students write research papers published on the basis of the practice project.

Therefore, teachers should constantly enrich and improve themselves, who constantly find themselves in the teaching process of shortage and gap, trying to find a variety of ways to learn and exercise, so as to build a high quality of "double type" teaching staff. If can arrange young teachers to get your credentials the exercise related certificates, business and teaching, production and research combined with common development pattern, such as improving teachers' practical ability. Only in the solid foundation on the basis of the theory and practice of combining education, has it been possible to develop a strategic vision and decision-making ability of automation.

\section{E. Vocational education}

Higher education was both high-level and applied. In view of the present automation major students' practical innovation ability is weak, and the employment goals are not clear and practical problems such as poor employment and expect too much. In addition to paying attention to cultivate students into society to adapt to the basic quality of survival, to cultivate students' career in the tourism industry of quality, especially professional awareness, professional attitude and professional ability, it is necessary as the main teaching content arrangement[6].

To sum up, based on MATLAB curriculum construction and reform, promoting the teacher-centered to student-centered teaching mode, to enhance the students' innovation ability, 
information consciousness and comprehensive quality, striving for teaching and research own features in or similar domestic colleges and universities in the province, providing the useful experience and enlightenment for the new situation, openness, construction and reform of innovative experiment.

\section{IMPLEMENTATION PLANS AND METHODS}

Under the guidance of constructionist to the training of specialists in the field of automation as the fundamental task, which takes promoting professional ability of automation industry as the main line, designing the students' knowledge, ability and quality structure and cultivation scheme, construction of curriculum and teaching system, etc., making the automation major students learned, capable, resourceful man, open-minded, intelligent and cultured man. Summarizing the successful experience of Chinese and foreign famous engineering schools, and comparing with the similar with the level of colleges and universities, to seek its automation major features in our school.

This topic research is based on the needs of the development of the automation industry to contact the relevant units, to understand the characteristics of the demand for automation talent, strengthening training pertinence and adaptability of the automation major.

\section{A. Characteristics of the comprehensive national colleges and universities.}

By going the way of open education, students can further achieve mastery through comprehensive professional course content and the study of electronic technology and the unity of MATLAB, which give students play to their creative ability of space and opportunities, students are in enthusiasm and a strong interest.

\section{B. Students' innovative consciousness and professional ability.}

Through the student check data, selecting design, programming and debugging the results of simulation analysis, the hardware circuit structures, and so on a series of work, opening the computer lab of MATLAB.

\section{CONCLUSION}

MATLAB curriculum reforms, combining the principle of automatic control, electronic technology courses with MATLAB computer simulation organically, which effectively improve the experimental teaching level of the students' self- innovation. Every other professional students who are interested for power electronic design can also be used as a benefit student.

Pioneering consciousness, innovation ability, scientific literacy, hands-on ability and teamwork spirit, etc., feeling the joy of success and the realization of self-worth, establishing the confidence of the scientific and technological innovation, and training and to develop the theory with practice, learning approach for the analysis of practical problems and solve practical questions.

\section{ACKNOWLEDGMENT}

This work is supported by Fundamental Research Funds for the Central Universities of Northwest Minzu University (Grant 31920160003, Grant 31920170079). And the project also supported by Experiment Funds of Northwest University for Nationalities, Northwest University for Nationalities, China. (Grant NO. SYSKF2017035, Grant NO. SYSKF2017036, Grant NO. SYSKF2017037, Grant NO. SYSKF2017043, Grant NO. SYSKF2017044).

Research Project on Entrepreneurship Education in Gansu Province in 2016:Research on the Innovation and Entrepreneurship Project of "Internet" in MingZu University, Department of Education in Gansu(2016SJCXCYJG1001.9150)

\section{REFERENCES}

[1] Lin Feng.Teaching Reform of Matlab and System Simulation Course.Journal of EEE.June 2015.Vol.37, No. 3.pp.12-14.

[2] Xu Qing-hong, Xing Can-hua, Lin Jian. Teaching Reform and Practice of MATLAB in Application-oriented Higher Institutions .The Science Education Article Collects. February 2015.No.306, pp.78-80.

[3] Kuai Song-yan,Heng Feng-ping,Cui Xin,Tan Guo-jun,Deng Xian-ming. Teaching Reform of Motion Control System Course Based on Matlab.January 2016.vol.38.No.1.pp.29-31.

[4] Yu Jian-jun, Li Hui-jie, Qiao Jun-fei, Yang Jin-fu, Han Hong-gui, Yan Ai-jun.Exploration and Innovation in the Practical Teaching of Automatic Control Theory :In the Case of Double Let Water Tank Liquid Level Control Experiment Based on MATLAB Real-Time Control. August 2016.No.247. pp.28-31.

[5] Wen Xiu-lan, Cao Wei-feng. The Exploration and Practice of Teaching Innovation for MATLAB and Signal Processing Simulation. China Modern Educational Equipment. January 2015. No.209.pp.39-41.

[6] Liu Yun-long, Wang Rui-lan, Liu Li-jun, Wang Wen-cheng. Reform on Experiment Teaching of Principle of Automatic Control Based on Matlab Simulation. Research and Exploration in Laboratory. Jun 2015.Vol.34, No.6,pp.102-106. 